\title{
Data-Driven Decisions in Employee Compensation utilizing a Neuro-Fuzzy Inference System
}

\author{
Caryl Charlene Escolar-Jimenez, DBA ${ }^{1}$, Kichie Matsuzaki, Ph.D. ${ }^{2}$, Koji Okada, Ph.D. ${ }^{3}$, \\ Reggie C. Gustilo, Ph.D. ${ }^{4}$ \\ ${ }^{1}$ Tokyo City University, Japan, caryl @tcu.ac.jp \\ ${ }^{2}$ Tokyo City University, Japan, matsuzak@ @cu.ac.jp \\ ${ }^{3}$ Tokyo City University, Japan,okadak@tcu.ac.jp \\ ${ }^{4}$ De La Salle University, Philippines, reggie.gustilo@dlsu.edu.ph
}

\begin{abstract}
Artificial intelligence assists organizations to carry out strategic management decisions especially in talent management. A firm's overall compensation management is defined by its pay philosophy and process that has been a key component in employee engagement and satisfaction that also correlates with firm success. This neuro-fuzzy inference system was able to design an objective compensation algorithm that objectively identified relevant variables for qualified applicants in the hiring and selection stage that will be the baseline of an employee's initial salary. The output is a salary grade matrix that allows adjustment discretion according to the standards of the HR department who may have preference to either one of the variables. This will now simultaneously function as an operational framework in the performance management stage for current employees and serve as a benchmark during annual salary reviews. An artificial neural network employed all parameters in the categorical traits in the performance evaluation of employees that targets errors that are not normally detected in the traditional review method that is subjected to preferential bias, favoritism or irregularities. The ANN structure output produced 5 numerical decisions to upgrade, maintain and downgrade the salary grade that will coincide with both organizational objectives and HR compensation policies.
\end{abstract}

Key words: Artificial intelligence, Compensation, HR analytics, Management, Neural-Fuzzy Inference System, Performance Evaluation, Salary Grade

\section{INTRODUCTION}

The emergence of artificial intelligence and automation has greatly affected the operating workplace environment of many organizations. The crucial role of artificial intelligence techniques to the human resource management (HRM) is data algorithm management to improve the decision making quality across all $\mathrm{HR}$ functions related to talent management.

Artificial intelligence is most commonly used for talent acquisition but $\mathrm{AI}$ and advanced big data analysis can also be utilized to make strategic and employee management decisions, analyze work policies and automate employee tasks. These pave the way for better workplaces as employees feel more engaged from the start of employment and would stay committed to working towards achieving organizational goals.

Studies have continuously highlighted the correlation of motivated and enthusiastic employees to the performance success of organizations by advocating that human resource strategy (including pay) should be treated as an integral component of corporate strategy [1]. When organizations focus on employee engagement and satisfaction, they do not only attract quality talent but also retain high performing employees in the long term.

Changes in the global economy have affected compensation and wage structures that are forcing companies to develop new compensation programs to fit new market-driven requirements [2] of employees. Therefore, data or predictive analytics can be utilized by HR to assess pay equity to eliminate discriminatory pay practices based on gender, race and ethnicity, and credential biases present in many organizations. Furthermore, these can monitor gaps and discrepancies in the system to assists HR and decision-makers in the organization to reduce employee turnover rate and concurrently empower employees by valuing and appreciating their contributions.

Employee engagement and satisfaction is likewise driven by a firm's overall compensation management that defines its pay philosophy and process. And one role of HR is to be able to fully explain well how salary grades are set and how an employee's salary is equitably determined and established during the compensation process. 
An employee's salary is an agreed upon fixed amount of money between the employer and the employee paid at regular intervals prior to employment. Additionally, this is an important aspect in the performance evaluation that will serve as a criterion for reward decisions whether to promote, train and develop in 1 or 2 trait areas [3] for achieving a certain level of productivity and efficiency.

The motivation of this research is to design an efficient [4] artificial intelligence compensation system that will objectively identify relevant variables for qualified applicants [5], determine an employee's fixed salary in the hiring and selection stage and at the same time, compliment all the other integrated areas in the HR functional framework as illustrated in Figure 1.

Overall, this will improve the compensation system utilized by most organizations and enable HR departments to increase their strategic advantage and attract and retain qualified employees by making more informed decisions.

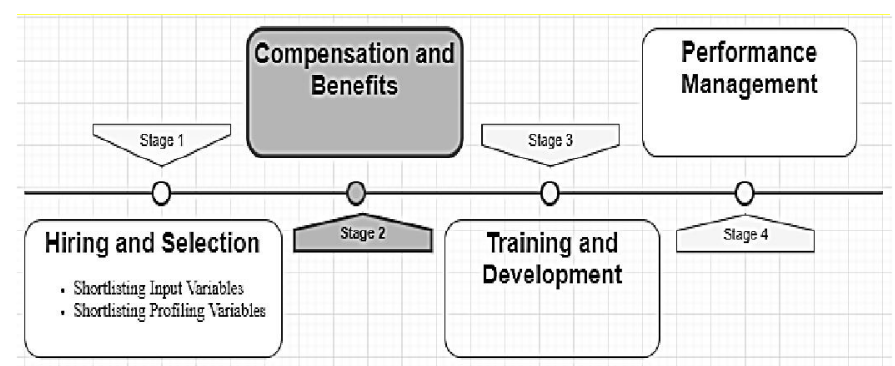

Figure 1: HR Analytics Functional Area Framework

\section{PROBLEM STATEMENT}

As the world's economy evolves continually into a complex and interrelated system, appropriately compensating employees has been an increasingly complicated task in finding, motivating and retaining talent [6] for many organizations.

One of the drivers for employee engagement is to motivate workers through pay and benefits [7] combined with a corporate culture that fosters teamwork, pleasant working conditions and others. Compensation is one of the important considerations why an employee considers whether to accept a job and usually a reason for an employee to leave the organization. Therefore, it is imperative for firms to have clear guidelines to help avoid differing treatment of individuals, while at the same time, reassuring the employee that the package is fair and reasonable [8].

Perspectives in HRM are expanding throughout the years and literature has always linked the relationship of strategies and reward systems to organizational performance. Studies emphasize that it is crucial for employees to be motivated by an appropriate reward package to further company goals but unfortunately, compensation packages intended to motivate employees frequently fail [1] as reasons emanate from inadequacies in the compensation design system or poor administration of incentives. These constrain organizations and lead to incremental talent attrition that not only creates more performance problems but also increases the cost to replace an employee.

Therefore, it is crucial that talent retention is supported by managerial practices that have consistent pay equity while keeping with its procedural justice [9]. These must focus on the variables affecting the pay mix structure as well as consider its correlation with the HR hiring and selection and the performance management stages.

\section{DESIGN PROCESS}

The proposed compensation system in Figure 2 will detect inaccuracies and overcome data errors [10] to eliminate subjectivity and bias that normally occurs from these $2 \mathrm{HR}$ functional stages. This also enables HR to make objective and informed decisions that is crucial to the overall performance of an organization.

Fuzzy logic was utilized to identify a fair salary grade prior to employment then an artificial neural network will then determine output decisions namely: upgrade, maintain or downgrade salary grade that is linked to the performance evaluation of employees.

Upgrading, maintaining or downgrading of salary grade decisions will stem from current employee attainments related to an individual's personal achievements or contributions to the organization.

The weights assigned in each variable are tunable according to the HR and the acquiring department. Updating of job grades every 2-3 years is important to ensure accurate salary information is based on changing market trends and conditions.

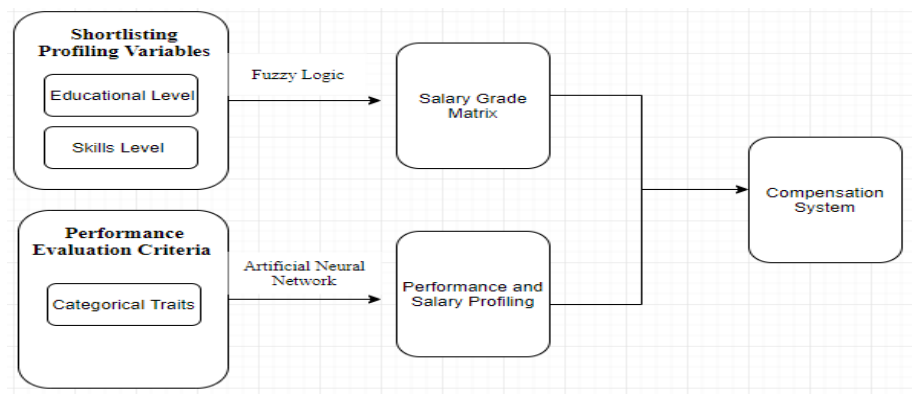

Figure 2: Overview of the Employee Compensation System

\section{RESULTS AND DISCUSSION}

This section discussed the algorithm used and outputs obtained from the proposed system in determining the proper compensation of employees. 


\subsection{Salary Grade}

The role of the salary grade is to assist employers to control pay expenses and to ensure pay equity among its employees. The job grade categorizes similar positions according to its worth and decides the impact, seniority and expectations for a specific role. HR can design as many or few pay grades as they deem it fit as long as the educational and skills level are considered.

For newly hired employees, the determination of the initial salary is crucial and a very important part in HR management. The results from the previous research on the proposed shortlist profiling algorithm predicted and filtered mechanisms to measure a candidate's alignment to a specific job post, predicting their possible future performance by ranking each individual candidate in real time. This ensures organizations are effective in their outcome-focused hiring of employees as candidates are judged based on their credentials and scored accordingly on how well they fit the criteria [5].

Data derived from the previous research computed the corresponding salary grade that fits a particular employee. The fuzzy inference system's function was to balance the skills and educational background of an employee as a typical practice of firms is give preference to either one of the variables resulting to a variance in the computation in the initial salary. Figure 3 illustrates the fuzzy logic structure wherein the educational level and skills level serve as inputs to the fuzzy logic system that will compute the initial hiring salary grade of a new employee.

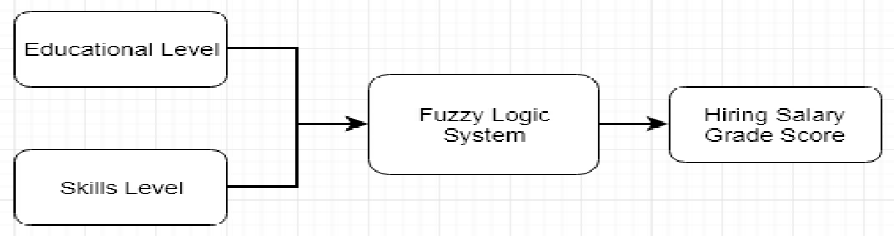

Figure 3: Fuzzy Inference System in Computing for the Hiring Salary Grade Score

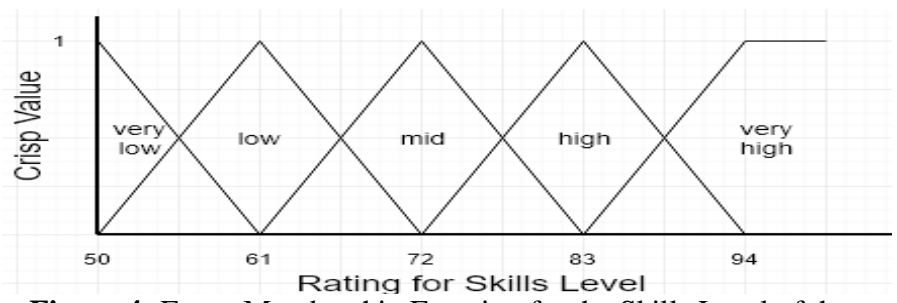

Figure 4: Fuzzy Membership Function for the Skills Level of the Employee for Hiring

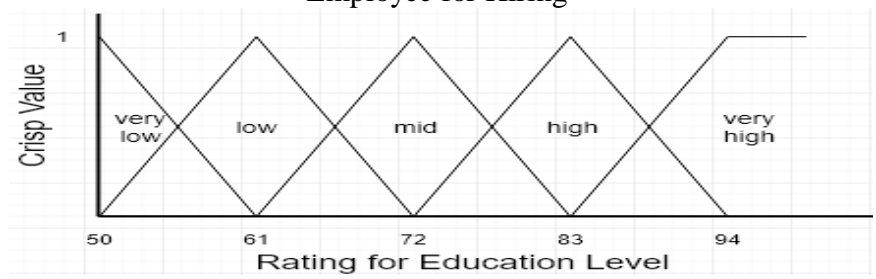

Figure 5: Fuzzy Membership Function for the Educational Level of the Employee for Hiring
Figure 4 and Figure 5 distinguished the fuzzy membership functions for the skills level and educational level respectively. An evaluation score of 50 either on the educational level or the skills level indicates that the employee's profile is in its lowest baseline grade.

The fuzzy logic algorithm employed both the educational and skills level to compute the corresponding salary grade of the employee. The fuzzy associative matrix used in the proposed method is shown in Figure 6.

\begin{tabular}{|c|c|c|c|c|c|c|}
\hline \multicolumn{7}{|c|}{ Salary Grade } \\
\hline \multirow{7}{*}{ 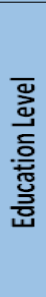 } & & \multicolumn{5}{|c|}{ Skills Level } \\
\hline & & $\begin{array}{l}\text { very } \\
\text { low }\end{array}$ & low & mid & high & $\begin{array}{l}\text { very } \\
\text { high }\end{array}$ \\
\hline & $\begin{array}{l}\text { very } \\
\text { low }\end{array}$ & 1 & 2 & 4 & 7 & 11 \\
\hline & low & 2 & 3 & 5 & 8 & 12 \\
\hline & mid & 4 & 5 & 6 & 9 & 13 \\
\hline & high & 7 & 8 & 9 & 10 & 14 \\
\hline & $\begin{array}{l}\text { very } \\
\text { high }\end{array}$ & 11 & 12 & 13 & 14 & 15 \\
\hline
\end{tabular}

Figure 6: Fuzzy Association Matrix in Computing for Salary Grade Using Educational Level and Skills Level as Inputs

The output in the fuzzy inference system is the hiring salary grade score that will determine the appropriate salary grade of an employee as reflected in the salary grade matrix in Table 1. This proposed algorithm will function as a reliable compensation matrix to be utilized as an operational framework for employee performance evaluations and serve as a benchmark for salary reviews. This matrix applied 15 salary grade levels that allows adjustment discretion according to the preferential standards of the HR department.

Table 1: Fuzzy Logic Score and Corresponding Salary Grade for Employees for Hiring

\begin{tabular}{|c|c|}
\hline Fuzzy Logic Score & Salary Grade \\
\hline$>=50$ but $<53$ & 1 \\
\hline$>=53$ but $<56$ & 2 \\
\hline$>=56$ but $<59$ & 3 \\
\hline$>=59$ but $<62$ & 4 \\
\hline$>=62$ but $<65$ & 5 \\
\hline$>=65$ but $<68$ & 6 \\
\hline$>=68$ but $<71$ & 7 \\
\hline$>=71$ but $<74$ & 8 \\
\hline$>=74$ but $<77$ & 9 \\
\hline$>=77$ but $<80$ & 10 \\
\hline$>=80$ but $<83$ & 11 \\
\hline$>=83$ but $<87$ & 12 \\
\hline$>=87$ but $<91$ & 13 \\
\hline$>=91$ but $<94$ & 14 \\
\hline$>=94$ & 15 \\
\hline
\end{tabular}




\subsubsection{Sample Result of determining appropriate Salary Grade}

To confirm the effectiveness of the proposed algorithm, a fuzzy logic system was used to determine the appropriate salary grades of 5 shortlisted applicants. Table 2 below reflected the applicant profile details and the resulting salary grades.

Table 2: Sample Result of Determining Salary Grade Score and their Corresponding Salary Grades

\begin{tabular}{|c|c|c|c|c|}
\hline Applicant & $\begin{array}{c}\text { Educat } \\
\text { ional } \\
\text { Level }\end{array}$ & $\begin{array}{c}\text { Skills } \\
\text { Level }\end{array}$ & $\begin{array}{c}\text { Salary } \\
\text { Grade } \\
\text { Score }\end{array}$ & $\begin{array}{c}\text { Corresponding } \\
\text { Salary Grade }\end{array}$ \\
\hline A & 100 & 85.00 & 89.5455 & SG13 \\
\hline B & 50 & 90.00 & 75.6364 & SG9 \\
\hline C & 50 & 72.50 & 59.4091 & SG4 \\
\hline D & 100 & 92.32 & 91.5418 & SG14 \\
\hline E & 50 & 79.00 & 64.7273 & SG5 \\
\hline
\end{tabular}

The educational and skills level variables both received equal weights in this shortlisting simulation and the results in Table 2 reflected differing salary scores and corresponding salary grades. This will achieve a balanced assessment in the salary grade determination of the 5 shortlisted applicants. Moreover, the variable weights in this proposed algorithm may be adjusted and tuned according to the preference of the HR who would give particular importance with one of the indicated variables.

\subsection{Salary Reviews for Current employees using Artificial Neural Network}

Many organizations want to recognize and reward performing employees with more money and execute measurable actions to improve non-performers. Thus, annual salary reviews are integral to firms as these normally converge with merit increases and performance evaluations. An effective salary review upholds an equitable distribution that assures top performers to receive the maximum possible rewards and at the same time, provide a platform to discuss an employee's achievements and shortcomings in line with their job duties.

Moreover, the salary review process enables HR not only to make informed decisions on the promotion, retention or termination aspect of employees but allows HR to analyze how compensation fits into the overall organizational budget to determine whether salary adjustments such as merit increases and bonuses are appropriate.

The proposed method for the salary review for current employees is an artificial neural network to assess whether a salary change is warranted. Since the algorithm recognizes patterns from real data, this becomes objective and prevents human errors [11] as opposed to the traditional method that is normally subjected to preferential bias, favoritism or irregularities.
The proposed method in Figure 7 below is an artificial neural network that will employ all parameters of the categorical traits in the performance evaluation of employees that targets defects with accuracy [12] that is not normally detected in the traditional review method.

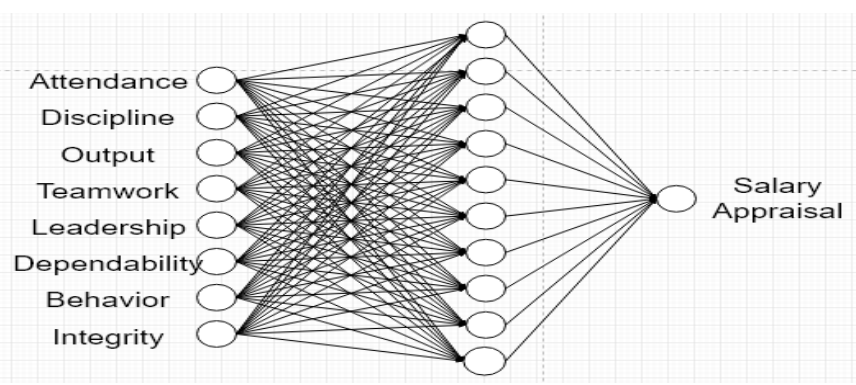

Figure 7: Structure of Artificial Neural Network with 8 inputs, 10 neurons and 1 output parameter

The artificial neural network dataset consists of 2500 sample data that has 1 hidden layer that utilized the LevendergMarquardt as its training algorithm. Table 3 below summarizes the performance of the artificial neural network with a reliability of $99 \%$.

Table 3: Dataset used in Artificial Neural Network

\begin{tabular}{|c|c|c|}
\hline & Samples & $\begin{array}{c}\text { Coefficient of } \\
\text { Correlation }\end{array}$ \\
\hline Training & 1750 & 0.99999 \\
\hline Validation & 375 & 0.99999 \\
\hline Testing & 375 & 0.99999 \\
\hline
\end{tabular}

The dataset consisting of 2500 employees were generated that revealed different employee profiles. These profiles are similar to the traditional method that utilizes a certain weight on each criterion that sums up to 100 percent. Each profile was appraised as either qualified to receive a salary increase, retain their current salaries or downgrade their current salaries due to non-performance.

The ANN structure output will produce 5 numerical decision scores with an appropriate interpretation as indicated in Table 4. The interpretation decision to upgrade, maintain and downgrade salary grade must coincide with both organizational objectives and HR compensation policies. The recommended approaches for employees who exemplify strong performance should be recognized with merit increases while for underperformers who are still considered valuable to the organization but do not thrive in their current role, maybe reassigned or demoted to another positon with lesser responsibilities. A termination decision is often the final recourse of HR for employees demonstrating consistent poor and disruptive performance.

When deciding on the rewards for performers and measurable actions for non-performers, it is integral that HR must be specific and consistent with their policies enforced through a 
reasonable process of assessment to assure employees that they were appropriately evaluated.

Table 4: Reviewed Salary Matrix Scheme of the Artificial Neural Network

\begin{tabular}{|c|c|c|}
\hline $\begin{array}{c}\text { Employee Profiles as } \\
\text { Interpreted by the } \\
\text { Neural Network }\end{array}$ & $\begin{array}{c}\text { Output of the } \\
\text { Neural Network }\end{array}$ & Decision \\
\hline $\begin{array}{c}\text { Outstanding } \\
\text { performance in all } \\
\text { categories }\end{array}$ & 2 & $\begin{array}{c}\text { Upgrade salary } \\
+2\end{array}$ \\
\hline $\begin{array}{c}\text { Very Satisfactory } \\
\text { performance except } \\
\text { in some traits }\end{array}$ & 1 & $\begin{array}{c}\text { Upgrade salary } \\
+1\end{array}$ \\
\hline $\begin{array}{c}\text { Satisfactory in all } \\
\text { categories }\end{array}$ & 0 & $\begin{array}{c}\text { Maintain Salary } \\
\text { Moderately } \\
\text { satisfactory except in } \\
\text { some traits }\end{array}$ \\
\hline $\begin{array}{c}\text { Improvement in the } \\
\text { majority of traits }\end{array}$ & -1 & $\begin{array}{c}\text { Downgrade } \\
\text { salary }-1 \text { for } \\
\text { possible } \\
\text { reassignment or } \\
\text { termination }\end{array}$ \\
\hline
\end{tabular}

To fully test the reliability of the proposed artificial neural network in the salary review, it considered the performance evaluation results of 7 employees in Table 5.

With the traditional method, the assignment of weights in each trait parameter will sum up to 100 percent that has revealed deficiencies in projecting the real performance of an employee. The biased outcome that may stem from differences in perception [13] in the traditional method will furthermore exacerbate issues inherent in performance reviews that will eventually hurt and affect employee morale. Results from the traditional method reflected that Employee A achieved a higher rating score than Employee B even if Employee A was not consistent with his performance particularly in his output and behavior traits which is not at all outstanding. This is a stark contrast with Employee B who has achieved outstanding ratings in all categorical traits.

Table 6 was able to distinguish individuals who were performing and non-performing from the established categorical traits in the employee performance evaluation. Employee A and E performed very satisfactory and will both receive a 1 salary grade increase while Employee C and D were satisfactory in their performance and will maintain their current salary grade. Moreover, Employee B was outstanding in his performance and will receive a 2 salary grade increase. However, Employee F will receive a 1 salary grade decrease for a moderately satisfactory performance and Employee G will receive a 2 salary grade decrease for performing poorly.

This proposed artificial neural network was able to present a robust and effective [14] mechanism for real-time [15] feedback on an employee's individual performance and organizational contributions. The numerical decisions performed clear and concise feedback that will enable HR and decision makers to recognize employee talent and growth opportunities beforehand. This allows organizations to efficiently manage, lower overall cost and achieve long-term operational success by communicating accurate results, avoiding legal risks and enhancing employee morale.

Table 5: Employees Evaluation Results and their Salary Appraisals by Traditional Method

\begin{tabular}{|c|c|c|c|c|c|c|c|c|c|}
\hline 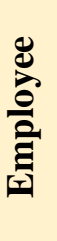 & 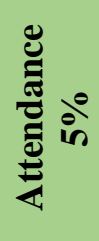 & 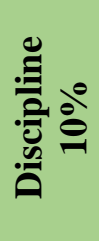 & 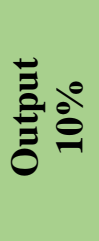 & 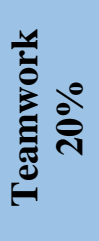 & 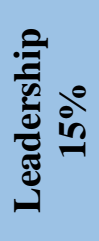 & 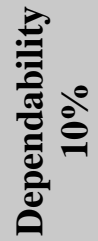 & 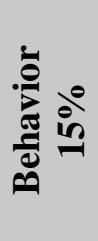 & 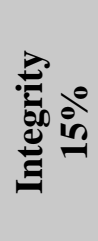 & 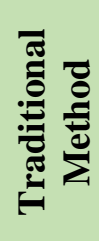 \\
\hline$\overline{\mathbf{A}}$ & 100 & 98 & 84 & 98 & 85 & 100 & 84 & 100 & 90.15 \\
\hline B & 89 & 90 & 88 & 89 & 90 & 91 & 90 & 90 & 85.75 \\
\hline $\bar{C}$ & 95 & 98 & 75 & 97 & 75 & 96 & 75 & 95 & 86.15 \\
\hline D & 95 & 98 & 75 & 97 & 75 & 96 & 75 & 95 & 86.15 \\
\hline $\mathbf{E}$ & 100 & 99 & 98 & 92 & 93 & 95 & 80 & 85 & 88.9 \\
\hline $\mathbf{F}$ & 62 & 85 & 88 & 84 & 88 & 66 & 88 & 65 & 76.35 \\
\hline $\bar{G}$ & 50 & 70 & 55 & 71 & 55 & 50 & 55 & 50 & 59.55 \\
\hline
\end{tabular}


Table 6: Comparison between the Proposed Neuro-fuzzy Performance and Salary Profiling System and the traditional method

\begin{tabular}{|c|c|c|c|c|c|c|c|c|c|c|}
\hline \multirow[b]{2}{*}{ 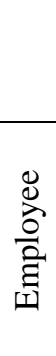 } & \multicolumn{8}{|c|}{ Categorical Traits } & \multirow{2}{*}{ 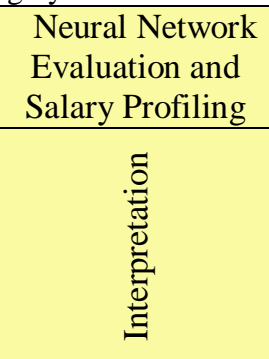 } & \multirow[b]{2}{*}{ 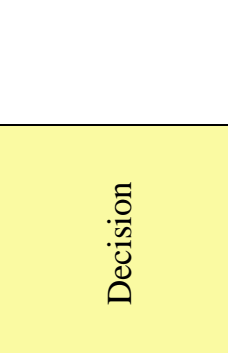 } \\
\hline & 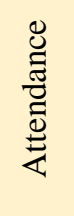 & 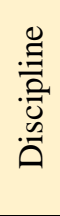 & 言 & 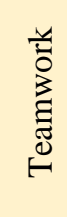 & 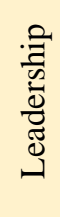 & 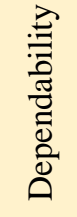 & 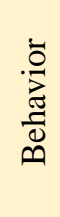 & 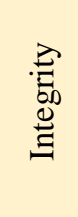 & & \\
\hline A & 100 & 98 & 84 & 98 & 85 & 100 & 84 & 100 & Very Satisfactory & $\begin{array}{c}\text { Upgrade salary } \\
+1\end{array}$ \\
\hline B & 89 & 90 & 88 & 89 & 90 & 91 & 90 & 90 & Outstanding & $\begin{array}{c}\text { Upgrade salary } \\
+2\end{array}$ \\
\hline $\mathrm{C}$ & 95 & 98 & 75 & 97 & 75 & 96 & 75 & 95 & Satisfactory & Maintain salary \\
\hline D & 95 & 98 & 75 & 97 & 75 & 96 & 75 & 95 & Satisfactory & Maintain salary \\
\hline $\mathrm{E}$ & 100 & 99 & 98 & 92 & 93 & 95 & 80 & 85 & Very Satisfactory & $\begin{array}{c}\text { Upgrade salary } \\
+1\end{array}$ \\
\hline $\mathrm{F}$ & 62 & 85 & 88 & 84 & 88 & 66 & 88 & 65 & $\begin{array}{l}\text { Moderately } \\
\text { Satisfactory }\end{array}$ & $\begin{array}{l}\text { Downgrade } \\
\text { salary -1 }\end{array}$ \\
\hline $\mathrm{G}$ & 50 & 70 & 55 & 71 & 55 & 50 & 55 & 50 & $\begin{array}{l}\text { Poor/Needs } \\
\text { Improvement }\end{array}$ & $\begin{array}{l}\text { Downgrade } \\
\text { salary -2 }\end{array}$ \\
\hline
\end{tabular}

\section{CONCLUSION}

The implementation of consistent and appropriate organizational practices is instrumental for firms to attract, motivate and retain qualified employees. Employee engagement highly correlates with the HR hiring and selection and the performance management stages as an attractive and competitive compensation structure should be able to satisfy the needs of a market-driven workforce.

Organizations often utilize traditional methods in the aforementioned stages that confines firms to be subjective and inaccurate in talent management decisions that impedes its competitive advantage.

A fuzzy logic profiling system produced a reliable compensation matrix to determine the initial hiring salary of an employee based on a set of criteria. This will serve as an operational guide for HR later on for salary reviews and benchmark against external market conditions. In addition, the artificial neural network was significant to determine whether a salary change is justified during the annual salary review of current employees.

With this intelligent algorithm, employees remain engaged and motivated because they know they are being fairly compensated, understand the logic and opportunity of how salary merit increases or downgrading to another job with a lower pay grade was determined and established during the salary review and performance evaluation process. Therefore, this enables organizations to remain competitive yet maintain a shared culture of equity and fairness.

\section{REFERENCES}

[1] Balkin, D.B. and Gomez $\square$ Mejia, L.R. Toward a contingency theory of compensation strategy. Strategic Management Journal, Vol. 8.2, pp.169-182, 1987.

https://doi.org/10.1002/smj.4250080207

[2] Hansen, F. New Compensation \& Benefits Resources. Compensation \& Benefits Review, Vol.31.3, pp.60-64, 1999.

https://doi.org/10.1177/088636879903100310

[3] Escolar-Jimenez, C., Matsuzaki, K., \& Gustilo, R. A Neural-Fuzzy Network Approach to Employee Performance Evaluation. International Journal of Advanced Trends in Computer Science and Engineering, Vol. 8.3, pp. 573-581, 2019. https://doi.org/10.30534/ijatcse/2019/37832019

[4] Sahebjamnia, N. \& Fathollahi-Fard, A.M. A Lagrangian Relaxation-based Algorithm to solve a Collaborative Water Supply Chain Network Design Problem. International Journal of Emerging Trends in Engineering Research, Vol. 6.7 pp. 40-45, 2018. https://doi.org/10.30534/ijeter/2018/01672018

[5] Escolar-Jimenez, C., Matsuzaki, K., \& Gustilo, R. Intelligent Shortlisting Process for Job Applicants using Fuzzy logic-based Profiling. International Journal of Advanced Trends in Computer Science and Engineering, Vol. 8.3, pp. 567-572, 2019. https://doi.org/10.30534/ijatcse/2019/36832019

[6] Dwyer, T.D. Trends in global compensation. Compensation \& Benefits Review, Vol. 31.4, pp.48-53, 1999. 
[7] Rama Devi, V. Employee engagement is a two-way street. Human resource management international digest, Vol. 17.2, pp. 3-4, 2009. https://doi.org/10.1108/09670730910940186

[8] Latta, G.W. Expatriate policy and practice: A ten-year comparison of trends. Compensation \& Benefits Review, Vol. 31.4, pp.35-39, 1999.

[9] Bhattacharyya, D.K. Compensation and benefits program a mediating variable for talent retention: A study of two century-old Indian organizations. Compensation \& Benefits Review, Vol. 47.2, pp.75-80, 2015. https://doi.org/10.1177/0886368715584481

[10] Varalakshmi, L.M. \& Ramalingam, R. License Plate Character Recognition using Advanced Image Processing Techniques and Genetic Algorithm. International Journal of Emerging Trends in Engineering Research, Vol. 3.4 pp. 10-13, 2015.

[11] L. Villanueva and R. C. Gustilo. Artificial neural network based antenna sensitivity assignments for chaotic Internet Service Provider network architecture. Int. J. Eng. Technol.(UAE), vol. 7, pp. 14$17,2018$.
[12] S. G. E. Brucal, A. D. M. Africa and E. P. Dadios. Female voice recognition using artificial neural networks and MATLAB voicebox toolbox. J. Telecommun., Electron., Comput. Eng., vol. 10, pp. 133-138, 2018.

[13] A. D. M. Africa and J. S. Velasco. Development of a urine strip analyzer using artificial neural network using an android phone, ARPN J. Eng. Appl. Sci., vol. 12, pp. 1706-1713, 2017.

[14] M. N. Eman, M. K. Cabatuan, E. P. Dadios and L. A. G. Lim. Detecting and tracking female breasts using neural network in real-time, Proc. IEEE Reg. 10 Annu. Int. Conf. (TENCON), 2013. https://doi.org/10.1109/TENCON.2013.6718899

[15] D. D. Abinoja, M. A. Roque, R. Atienza and L. Materum, Landmark-based audio fingerprinting algorithm for a transmitter-less alert recognition device for the hearing-impaired. 8th Int. Conf. Human., Nanotechnol., Inf. Technol., Commun. Control, Env. Manag., HNICEM 2015, 2016. https://doi.org/10.1109/HNICEM.2015.7393228 